\title{
SISTEM PENDUKUNG KEPUTUSAN SELEKSI PENERIMAAN TENAGA KONTRAK DENGAN METODE SIMPLE ADDITIVE WEIGHTING (SAW) PADA KANTOR SATPOL PP KABUPATEN POHUWATO
}

\author{
Bahrin \\ bahrindahlan@gmail.com \\ Universitas Ichsan Gorontalo
}

\begin{abstract}
Abstrak
Kegiatan Seleksi tenaga kontrak merupakan kegiatan yang sering dilaksanakan oleh Kantor Satuan Polisi Pamong Praja Kabupaten Pohuwato. Kenyataan dilapangan bahwa pihak kantor kurang siap dalam penyelenggaraan seleksi Tenaga Kontrak. Masalah administrasi yang bersifat manual mengakibatkan kurang efisiennya kegiatan seleksi Tenaga Kontrak. Oleh karena itu, penulis berinisiatif untuk merancang suatu sistem yang dapat membantu pihak kantor dalam pengambil keputusan seleksi Tenaga Kontrak, sehingga dapat lebih efisien dalam pelaksanaannya. Ada beberapa model yang dapat digunakan untuk membangun sebuah sistem pendukung keputusan salah satunya adalah Fuzzy Multiple Attribute Decision Making (FMADM). Berdasarkan hasil penelitian Sistem Pendukung Keputusan yang sudah dibuat dapat membantu pihak pengambil keputusan dalam menentukan alternatif terbaik yaitu tenaga kontrak yang tepat. Hal ini dibuktikan dengan hasil pengujian yang dilakukan dengan metode white box testing dan bases path testing yang menghasilkan nilai $V(G)=C C$, dimana $V(G)=4$ dan $C C=4$, sehingga didapat bahwa logika flowchart perhitungan normalisasi dan perankingan benar dan berdasarkan pengujian black box yang meliputi uji input proses dan output dengan mengacu pada rancangan perangkat lunak telah terpenuhi dengan hasil sesuai dengan rancangan.
\end{abstract}

Kata Kunci : Fuzzy, Seleksi Penerimaan, Tenaga Kontrak

\section{Pendahuluan}

Kemajuan teknologi komputer sudah mengalami perkembangan yang pesat, berbagai kantor termasuk kantor yang bergerak di bidang keuangan sangat membutuhkan alat bantu dalam mengambil keputusan. Alat bantu tersebut adalah komputer yang salah satu fungsinya adalah pendukung dalam mengambil keputusan seorang pimpinan tingkat atas, teknologi informasi merupakan suatu usaha pengumpulan, penyimpanan, pengolahan, penyebaran dan pemanfaatan informasi yang meliputi bidang IPTEK dan perekayasaan serta teknik-teknik pengelolaannya. Dibeberapa wilayah masih ada berbagai kantor atau instansi pemerintah yang belum mengkomputerisasikan sistem penerimaan Tenaga Kontraknya dan masih dilakukan secara manual. Hal ini menyebabkan keterlambatan dalam pembuatan laporan yang berkaitan dengan lambatnya informasi sehingga akan banyak menyita waktu dan pengolahan data terhadap kesalahan lebih besar.

Kegiatan Seleksi tenaga kontrak merupakan kegiatan yang sering dilaksanakan oleh Kantor Satuan Polisi Pamong Praja Kabupaten Pohuwato. Kenyataan dilapangan bahwa pihak kantor kurang siap dalam penyelenggaraan seleksi Tenaga Kontrak. Masalah administrasi yang bersifat manual mengakibatkan kurang efisiennya kegiatan seleksi Tenaga Kontrak. Oleh karena itu, penulis berinisiatif untuk merancang suatu sistem yang dapat membantu pihak kantor dalam pengambil keputusan seleksi Tenaga Kontrak, sehingga dapat lebih efisien dalam pelaksanaannya. Ada beberapa model yang dapat digunakan untuk membangun sebuah sistem pendukung keputusan salah satunya adalah Fuzzy Multiple Attribute Decision Making (FMADM)

Untuk mengetahui pengambilan keputusan tersebut akurat atau tidak, harus dilakukan penilaian dengan kriteria yang telah ditentukan selain dari nilai tes kriteria lain yang dibutuhkan dalam sistem penerimaan Tenaga Kontrak adalah pengalaman dan hasil psikotest yang bersangkutan. Sehingga dari hasil penilaian tersebut pihak kantor dapat mengambil sebuah keputusan sebagai bahan evaluasi untuk menerima Tenaga Kontrak yang mendaftar di Kantor Satuan Polisi Pamong Praja Kabupaten Pohuwato. 
Metode yang digunakan dalam sistem pendukung keputusan ini adalah Metode Simple Additive Weighting (SAW) karena metode ini menentukan nilai bobot untuk setiap atribut, kemudian dilanjutkan dengan proses perankingan yang akan menyeleksi alternatif terbaik, dalam hal ini alternatif yang dimaksud adalah alternatif calon Tenaga Kontrak yang di terima berdasarkan kriteria-kriteria yang ditentukan.

Penelitian bertujuan untuk mengetahui cara merekayasa Sistem Pendukung Keputusan seleksi Penerimaan Tenaga Kontrak dengan Menggunakan Metode SAW pada Kantor Satpol PP Kab. Pohuwato.

\section{Landansan Teori}

Secara sederhana, suatu seleksi tenaga kerja diartikan sebagai suatu proses pemilihan beberapa orang dari sekumpulan orang-orang dengan preferensi tertentu. Preferensi yang dimaksud adalah hanya kualifikasi personil yang dibutuhkan sesuai dengan persyaratan jabatanya. Namun demikian, pelaksanaannya sering kali ada pertimbangan-pertimbangan lain seperti hubungan keluarga, kawan dekat, serta hubungan kekerabatan semacam itu, ikut dipergunakan sebagai preferensi dalam pemilihan tenaga kerja.

Selanjutnya dikatakan, dalam bidang ketenaga kerjaan pengertian seleksi mengandung arti pengambilan keputusan tentang memperkerjakan sejumlah tenaga kerja dari suatu kelompok calon tenaga kerja yang potensial. Dengan pengertian semacam itu, maka dapat diketahui bahwa suatu seleksi tenaga kerja dilakukan dengan tujuan untuk mencari atau memilih tenaga kerja yang sesuai dengan persyaratan dan kualifikasi jabatan tertentu. Adapun persyaratan untuk memenuhi seleksi penerimaan ketenaga kerjaan di Satpol-PP Kab. Pohuwato yaitu:

\subsection{Ketentuan Umum}

1. Warga Negara Republik Indonesia, bertaqwa kepada Tuhan Yang Maha Esa, setia dan taat kepada Pancasila, UUD 1945, dan memiliki integritas tinggi terhadap Negara Kesatuan Republik Indonesia;

2. Berkelakuan baik dan tidak pernah dihukum penjara atau kurungan berdasarkan keputusan pengadilan yang memiliki kekuatan hukum tetap (dibuktikan dengan SKCK yang masih berlaku);

3. Sehat jasmani, rohani/mental dan tidak memiliki kelainan yang dapat mengganggu pelaksanaan pekerjaan (dibuktikan dengan surat keterangan kesehatan dari dokter Pemerintah yang masih berlaku);

4. Bebas Narkoba (dibuktikan dengan surat keterangan bebas narkoba dari BNN (Badan Narkotika Nasional) Kabupaten Pohuwato.

5. Diutamakan pelamar yang berdomisili di Kabupaten Pohuwato (dibuktikan dengan KTP berdomisili di Pohuwato selama 2 Tahun);

6. Pelamar menandatangani surat pernyataan bermaterai Rp. 6.000,- bahwa :

a. Tidak pernah diberhentikan dengan tidak hormat sebagai pegawai/karyawan pada perusahaan;

b. Bersedia ditempatkan di seluruh wilayah Kabupaten Pohuwato;

c. Tidak sedang dalam masa pendidikan dan tidak sedang terikat kontrak dengan pihak manapun;

d. Pada saat mendaftar dan selama masa kontrak tidak diperkenankan untuk hamil (bagi perempuan);

\subsection{Ketentuan Khusus}

1. Memiliki kompetensi pendidikan sekurang-kurangnya SLTA atau sederajat sesuai formasi yang dipersyaratkan sebagai tenaga bantu bidang ketentraman masyarakat dan ketertiban umum dengan ketentuan :

a. Ijazah Negeri Sekolah Menengah Umum / Kejuruan dan sederajat harus mendapat pengesahan / dilegalisasi dari Kepala Sekolah yang bersangkutan;

b. Ijazah Swasta Sekolah Menengah Umum / Kejuruan dan sederajat harus mendapat pengesahan / dilegalisasi dari Dinas Pendidikan Setempat;

c. Surat Keterangan Lulus / ljazah sementara tidak dapat diterima;

2. Berusia minimum 20 (dua puluh) tahun dan maksimum 33 (tiga puluh tiga) tahun terhitung sejak tanggal ditetapkannya penerimaan seleksi Tenaga Kontrak;

3. Tinggi badan untuk laki-laki minimum $165 \mathrm{~cm}$ (seratus enam puluh lima sentimeter) dan untuk perempuan minimum $155 \mathrm{~cm}$ (seratus lima puluh lima sentimeter).

4. Pada saat klarifikasi pendaftaran, agar menunjukkan dokumen asli (ljazah dan lain-lain).

5. Tidak bertato dan bertindik [1];

Setelah program penarikan tenaga kerja selesai dilakukan, yaitu pada saat telah terkumpul sejumlah calon tenaga kerja yang memenuhi syarat umum yang dibutuhkan, maka proses 
selanjutnya yang harus dilaksanakan adalah melakukan pemilihan dari sekian banyak yang tersedia itu. Pemilihan atau lebih dikenal dengan istilah seleksi, dilakukan untuk memenuhi kebutuhan tenaga kerja yang telah ditetapkan dalam perencanaan sumber daya manusia.

\subsection{Pengertian Sistem Pendukung Keputusan}

Sistem Pendukung Keputusan (Decision Support Systems disingkat DSS) adalah bagian dari sistem informasi berbasis komputer termasuk sistem berbasis pengetahuan (manajemen pengetahuan) yang dipakai untuk mendukung pengambilan keputusan dalam suatu organisasi atau perusahaan. Dapat juga dikatakan sebagai sistem komputer yang mengolah data menjadi informasi untuk mengambil keputusan dari masalah semi-terstruktur yang spesifik [2].

Tujuan pembentukan SPK yang efektif adalah memanfaatkan keunggulan kedua unsur, yaitu manusia dan perangkat elektronik. Terlalu banyak menggunakan komputer akan menghasilkan pemecahan yang bersifat mekanis, reaksi yang tidak fleksibel, dan keputusan yang dangkal. Sedangkan terlalu banyak manusia akan memunculkan reaksi yang lamban, pemanfaatan data yang serba terbatas, dan kelambanan dalam mengkaji alternatif yang relevan. Guna membantu mempercepat dan mempermudah proses pengambilan keputusan, diperlukan suatu bentuk Sistem Pendukung Keputusan. Tujuannya adalah untuk membantu pengambil keputusan memilih berbagai alternatif keputusan yang merupakan hasil pengolahan informasi yang diperoleh/tersedia dengan menggunakan model pengambil keputusan [2].

Berdasarkan uraian di atas, sistem keputusan tidak bisa dipisahkan dari sistem fisik maupun sistem informasi. Kompleksitas sistem secara fisik menuntut adanya sistem keputusan yang komplek pula. Ciri utama dari sistem pendukung keputusan adalah kemampuannya untuk menyelesaikan masalah-masalah yang tidak terstruktur. Untuk menghasilkan keputusan yang baik di dalam sistem pendukung keputusan, perlu didukung oleh informasi dan fakta-fakta yang berkualitas antara lain:

a. Aksebilitas

Berkaitan dengan kemudahan mendapatkan informasi, informasi akan lebih berarti bagi pemakai kalau informasi tersebut mudah didapat.

b. Kelengkapan

Berkaitan dengan kelengkapan isi informasi, dalam hal ini isi tidak menyangkut hanya volume tetapi juga kesesuaian dengan harapan pemakai sehingga seringkali kelengkapan ini sulit diukur secara kuantitatif.

c. Ketelitian

Berkaitan dengan tingkat kesalahan yang mungkin di dalam pelaksanaan pengolahan data dalam jumlah (volume) besar.

d. Ketepatan

Berkaitan dengan kesesuaian antara informasi yang dihasilkan dengan kebutuhan pemakai.

e. Ketepatan Waktu

Kualitas informasi juga sangat ditentukan oleh ketepatan waktu penyampaian dan aktualisasinya.

f. Kejelasan

Berkaitan dengan bentuk atau format penyampaian informasi.

g. Fleksibilitas

Berkaitan dengan tingkat adaptasi dari informasi yang dihasilkan terhadap kebutuhan berbagai keputusan yang akan diambil dan terhadap sekelompok pengambil keputusan yang berbeda.

\section{Metode}

Simple Additive Weighting (SAW) sering juga dikenal istilah metode penjumlahan terbobot. Konsep dasar metode SAW adalah mencari penjumlahan terbobot dari rating kinerja pada setiap alternatif dari semua atribut. Metode SAW membutuhkan proses normalisasi matriks keputusan $(X)$ ke suatu skala yang dapat diperbandingkan dengan semua rating alternative yang ada. Diberikan persamaan sebagai berikut:

$$
r_{i j}= \begin{cases}\frac{x_{i j}}{\operatorname{Max}_{i} x_{i j}} & j i k a \mathrm{j} \text { atribut keuntungan (benefit) } \\ \frac{\operatorname{Minx}_{i j}}{x_{i j}} & \text { jika jatribut biaya (cost) }\end{cases}
$$

Di mana rij adalah rating kinerja ternormalisasi dari alternatif $\mathrm{Ai}$ pada atribut $\mathrm{Cj} ; \mathrm{i}=1,2, \ldots, \mathrm{m}$ dan $\mathrm{j}=1,2, \ldots, \mathrm{n}$. Nilai preferensi untuk setiap alternative $(\mathrm{Vi})$ diberikan rumus sebagai berikut:

$$
V_{i}=\sum_{j=1}^{n} w_{j} r_{i j}
$$


Nilai Vi yang lebih besar mengindikasikan bahwa alternatif Ai lebih terpilih.

Contoh : Suatu institusi Perguruan Tinggi akan memilih seorang karyawannya untuk dipromosikan sebagai kepala unit sistem informasi.

Ada empat kriteria yang digunakan untuk melakukan penilaian, yaitu:

- $\quad \mathrm{C} 1=$ tes pengetahuan (wawasan) sistem informasi

- $\quad \mathrm{C} 2$ = praktek instalasi jaringan

- $\quad \mathrm{C} 3=$ tes kepribadian

- $\quad$ C4 = tes pengetahuan agama

Pengambil keputusan memberikan bobot untuk setiap kriteria sebagai berikut : $\mathrm{C} 1=35 \%$; 2

$=25 \%$; C $3=25 \%$; dan C4 $=15 \%$.

Ada enam orang karyawan yang menjadi kandidat (alternatif) yaitu:

- $\quad A 1=$ Indra,

- $\quad \mathrm{A} 2=$ Roni,

- $A 3=$ Putri,

- $\quad$ A4 = Dani,

- $\mathrm{A} 5$ = Ratna,

- $\quad$ dan A6 = Mira

Tabel 1 Tabel Nilai Alternatif Kriteria [3]

\begin{tabular}{lcccc}
\hline \multirow{2}{*}{ Alternatif } & \multicolumn{5}{c}{ Kriteria } \\
\cline { 2 - 5 } Indra & C1 & C2 & C3 & C4 \\
Roni & 70 & 50 & 80 & 60 \\
Putri & 50 & 60 & 82 & 70 \\
Dani & 85 & 55 & 80 & 75 \\
Ratna & 82 & 70 & 65 & 85 \\
Mira & 75 & 75 & 85 & 74 \\
\hline
\end{tabular}

Normalisasi :

$$
\begin{aligned}
& \mathrm{r}_{11}=\frac{70}{\max \{70 ; 50 ; 85 ; 82 ; 75 ; 62\}}=\frac{70}{85}=0,82 \\
& \mathrm{r}_{21}=\frac{70}{\max \{70 ; 50 ; 85 ; 82 ; 75 ; 62\}}=\frac{50}{85}=0,59 \\
& \mathrm{r}_{12}=\frac{50}{\max \{50 ; 60 ; 55 ; 70 ; 75 ; 50\}}=\frac{50}{75}=0,67
\end{aligned}
$$

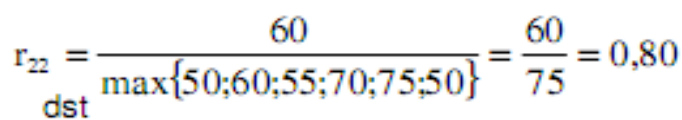

Hasil Normalisasi :

$$
R=\left[\begin{array}{cccc}
0,82 & 0,67 & 0,94 & 0,71 \\
0,59 & 0,80 & 0,96 & 0,82 \\
1 & 0,73 & 0,94 & 0,88 \\
0,96 & 0,93 & 0,76 & 1 \\
0,88 & 1 & 1 & 0,87 \\
0,73 & 0,67 & 0,88 & 0,94
\end{array}\right]
$$

Proses perankingan dengan menggunakan bobot yang telah diberikan oleh pengambil keputusan: $w=[0,350,250,250,15]$

Hasil yang diperoleh adalah sebagai berikut:

$$
\begin{aligned}
& \mathrm{V}_{1}=(0,35)(0,82)+(0,25)(0,67)+(0,25)(0,94)+(0,15)(0,71)=0,796 \\
& \mathrm{~V}_{2}=(0,35)(0,59)+(0,25)(0,80)+(0,25)(0,96)+(0,15)(0,82)=0,770 \\
& \mathrm{~V}_{3}=(0,35)(1,00)+(0,25)(0,73)+(0,25)(0,94)+(0,15)(0,88)=0,900 \\
& \mathrm{~V}_{4}=(0,35)(0,96)+(0,25)(0,93)+(0,25)(0,76)+(0,15)(1,00)=0,909 \\
& \mathrm{~V}_{5}=(0,35)(0,88)+(0,25)(1,00)+(0,25)(1,00)+(0,15)(0,87)=0,939 \\
& \mathrm{~V}_{6}=(0,35)(0,73)+(0,25)(0,67)+(0,25)(0,88)+(0,15)(0,94)=0,784
\end{aligned}
$$


Nilai terbesar ada pada V5 sehingga alternatif A5 adalah alternatif yang terpilih sebagai alternatif terbaik, dengan kata lain Ratna akan terpilih sebagai kepala unit sistem informasi [3].

\section{Hasil}

Pengujian sistem dilakukan setelah semua modul dibuat, dan sistem dapat berjalan. Pada tahap ini dilakukan pengujian sistem dari segi komponen dan integrasi dengan menggunakan teknik pengujian white box dan black box. Pada pengujian white box digunakan untuk menguji basis path dan menghitung nilai Cyclomatic Complexitynya, sedangkan pada pengujian black box berfokus pada persyaratan fungsional terhadap interface sistem pendukungan keputusan.

White box testing adalah metode desain test case yang menggunakan struktur kontrol desain prosedural untuk mendapatkan test case. Dalam pelaksanaannya, teknik pengujian white box ini mempunyai empat (4) langkah, yaitu sebagai berikut:

1. Menggambar flowgraph (Aliran Kontrol) yang ditransfer dari flowchart

2. Menghitung cyclomatic complexsity (CC) untuk flowgraph yang telah dibuat.

3. Menentukan jalur pengujian dari flowgraph berjumlah sesuai dengan cyclomatic complxity yang telah ditentukan

4. Bases path testing, yaitu teknik yang memungkinkan perancang test case mengukur kompleksitas logis dari desain procedural dan menggunakannya sebagai pedoman untuk menetapkannya basis set dari jalur eksekusi.

Hasil rancangan dengan menggunakan white box testing pada alur program, struktur logika program atau prosedur programnya dengan cara pemetaan flowchart ke dalam flowgraph kemudian menghitung besarnya jumlah edge dan node dimana jumlah edge dan node ini akan menentukan besarnya cyclomatic compexity (CC). Perhitungan CC untuk melihat kesamaan nilai antar white box testing, jika nilai $\mathrm{V}(\mathrm{G})=\mathrm{CC}$ pada white box testing dengan bases path testing maka proses pengujian telah berhasil.

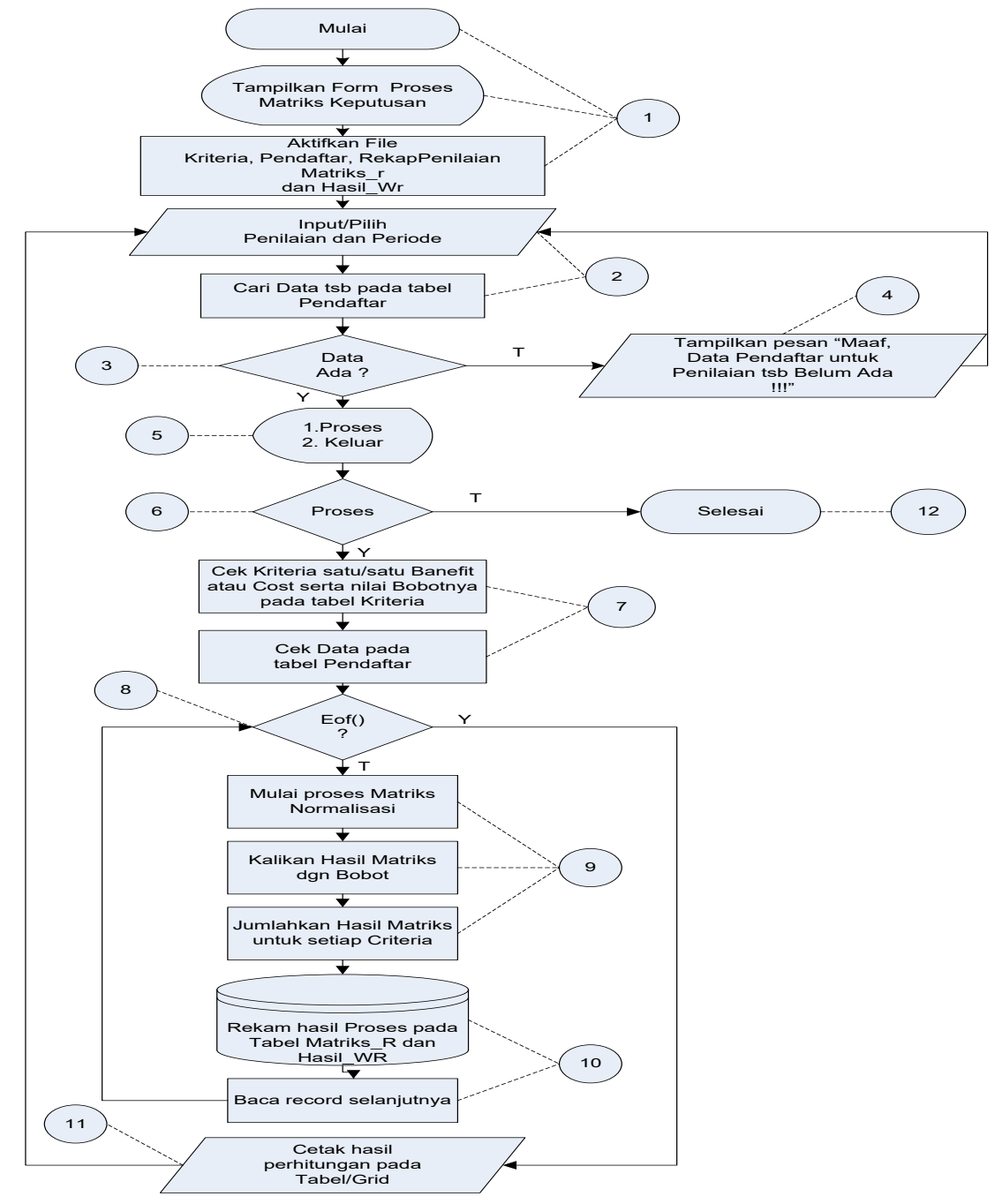

Gambar 1 Flowchart Pengujian 


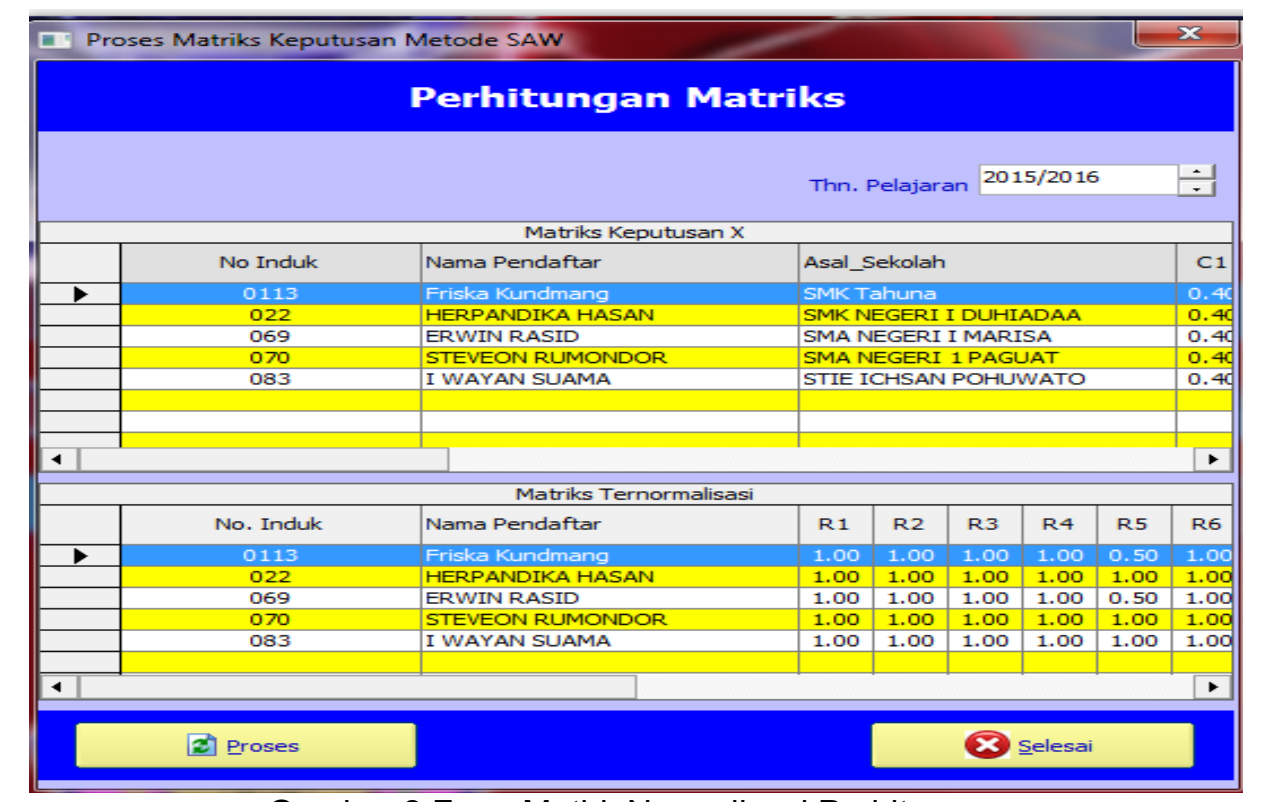

Gambar 2 Form Matirk Normalisasi Perhitungan

Pada form ini digunakan untuk menentukan Matriks normalisasi dari setiap kriteria. sistem akan menampilkan hasil proses normaliasi pada tabel kedua. Contoh Perhitungan Normalisasi dengan menggunakan salah satu jenis Penerimaan Tenaga Kontrak yaitu :

Matriks keputusan $\mathrm{X}$ dapat dilihat sebagai berikut :

× $\left\{\begin{array}{lllll}0.60 & 0.80 & 0.80 & 0.80 & 0.80 \\ 0.80 & 0.60 & 0.60 & 0.60 & 0.60 \\ 0,00 & 0.50 & 0.75 & 0.50 & 0.25 \\ 0.20 & 0.20 & 0,20 & 0.80 & 1.00 \\ 1.00 & 0.25 & 0.50 & 0.75 & 0.75 \\ 1.00 & 0.40 & 0.40 & 0.40 & 0.60 \\ 0.20 & 0.50 & 0.50 & 0.75 & 0.25 \\ 0.25 & 0.50 & 0.25 & 0.25 & 0.75 \\ 0,50 & 0.05 & 0.50 & 0,50 & 0.50 \\ 0.50 & 0.00 & 0.50 & 0.50 & 0.25\end{array}\right\}$

\section{Kesimpulan dan Saran}

\subsection{Kesimpulan}

Berdasarkan hasil penelitian yang sudah dilakukan dan hasil pengujian sistem, maka dapat disimpulkan bahwa :

1. Dapat diketahui cara merekayasa Sistem Pendukung Keputusan Seleksi Penerimaan Tenaga Kontrak dengan Menggunakan Metode SAW pada Satuan Polisi Pamong Praja Kab.Pohuwato.

2. Sistem Pendukung Keputusan Seleksi Penerimaan Tenaga Kontrak dengan menggunakan metode SAW yang sudah direkayasa dapat di implementasikan pada Satuan Polisi Pamong Praja Kab.Pohuwato. Untuk membantu pihak pengambil keputusan dalam menentukan siapa yang lebih berhak lulus penerimaan siswa karena sudah didasarkan pada kriteria-kriteria dan nilai bobot yang sudah ditentukan, karena sistem dibuat dengan menetukan nilai bobot untuk setiap atribut, kemudian dilakukan perankingan yang menentukan alternatif yang optimal yaitu siswa yang tepat lulus di Satuan Polisi Pamong Praja Kab.Pohuwato. Hal ini dibuktikan dengan hasil pengujian yang dilakukan dengan metode white box testing dan bases path testing yang menghasilkan nilai $V(G)=C C$, dimana $V(G)=4$ dan $C C=4$, sehingga didapat bahwa logika flowchart perhitungan normalisasi dan perankingan adalah benar dan berdasarkan pengujian black box yang meliputi uji input proses dan output dengan mengacu pada rancangan perangkat lunak yang sudah dibuat telah terpenuhi dengan hasil sesuai dengan rancangan. 


\subsection{Saran}

Berdasarkan pembahasan hasil penelitian dan kesimpulan di atas, saran-saran yang dapat diberikan penulis adalah sebagai berikut :

1. Sistem pendukung keputusan ini adalah hanya merupakan sebuah sistem untuk membantu pihak pengambil keputusan dalam menentukan pilihan yang optimal, bukan sistem penentu pengambilan keputusan.

2. Agar sistem dapat berjalan secara maksimal, maka diharapkan mengunakan perangkat komputer sesuai dengan spesifikasi minimal yang di sarankan.

\section{Daftar Pustaka}

[1]. Dinas Tenaga Kerja, 2014, Kantor Satpol PP Kabupaten Pohuwato 2015, Pohuwato, Diknakertrams.

[2]. Kusrini, 2008, Konsep dan Aplikasi Sistem Pendukung keputusan, Yokyakarta: Andi.

[3]. Kusumadewi, 2007, Pencarian Bobot Atribut Pada Multiple-Attribute Decision Making dengan Pendekatan Objektif Menggunakan Algoritma Genetika. 